\title{
Andrew T. Crislip, From Monastery to Hospital Christian Monasticism and the Transformationof Health Care in Late Antiquity
} Ann Arbor The University of Michigan Press, 2005, 235 p.

\section{Youhanna Nessim Youssef}

\section{OpenEdition}

\section{Journals}

Édition électronique

URL : http://journals.openedition.org/assr/3902

DOI : $10.4000 /$ assr.3902

ISSN : $1777-5825$

Éditeur

Éditions de l'EHESS

Édition imprimée

Date de publication : 1 décembre 2006

Pagination : 115-283

ISBN : 2-7132-2124-2

ISSN : 0335-5985

\section{Référence électronique}

Youhanna Nessim Youssef, «Andrew T. Crislip, From Monastery to Hospital Christian Monasticism and the Transformationof Health Care in Late Antiquity ", Archives de sciences sociales des religions [En ligne], 136 | octobre - décembre 2006, document 136-29, mis en ligne le 12 février 2007, consulté le 21

septembre 2020. URL : http://journals.openedition.org/assr/3902; DOl : https://doi.org/10.4000/assr. 3902

Ce document a été généré automatiquement le 21 septembre 2020.

(c) Archives de sciences sociales des religions 


\title{
Andrew T. Crislip, From Monastery to Hospital Christian Monasticism and the Transformationof Health Care in Late Antiquity
}

Ann Arbor The University of Michigan Press, 2005, 235 p.

\author{
Youhanna Nessim Youssef
}

1 Ce livre a fait le sujet d'une thèse soutenue à l'Université de Michigan sous la direction du professeur B. Layton, un coptisant distingué, c'est ainsi que près des trois quarts de la matière étudiée sont consacrées à l'Égypte chrétienne. Le livre s'ouvre sur une introduction où l'auteur passe en revue les divers aspects qui seront traités dans le livre.

2 Le premier chapitre traite des soins médicaux dans les monastères cénobitiques à propos desquels A.T. Crislip mentionne l'infirmerie connue seulement par certains textes sauf dans le cas du monastère de Saint-Jérémie à Saqqarah où ont été repérées les traces d'une pièce identifiée par les archéologues comme une infirmerie. L'auteur évoque ensuite les soins médicaux dans les laures en se basant essentiellement sur les textes littéraires. On s'étonne cependant de ne pas trouver le nom Jean Colobos (le nain) qui soigna son maître Ammoés pendant plusieurs années. ( $C f$. L. Regnault, « Le vrai visage d'un père du désert ou abba Jean Colobos à travers les apophtegmes ", Genève, Cahiers d'Orientalismes X, 1984, p. 26). L'auteur étudie le personnel médical, médecins, infirmiers, intendants et également les traitements y compris les «nonmedical Healing" à savoir les miracles. Le lecteur doit se référer à l'étude du professeur Antoine Guillaumont (Aux origines du monachisme chrétien. Pour une étude phénoménologie du monachisme, coll. "Spiritualité orientale et vie monastique » 30, Bégrolles-en-Mauges, Abbaye Bellefontaine, 1979). Les miracles sont souvent cités pour les moines des villes car il existe des disciples pour les noter alors que les moines du désert citent rarement des miracles. 
3 À ce sujet, il faut noter deux prières liturgiques de l'Église copte : l'oraison des malades dans la liturgie copte et le sacrement de l'onction des malades qui font partie des traitements non médicaux. Le chapitre se termine par l'étude des traitements médicaux y compris le régime alimentaire, le confort voire la chirurgie. Il faut cependant noter que l'auteur ne donne aucune conclusion sur les sujets traités.

4 Le deuxième chapitre étudie le soin médical monastique dans un contexte fonctionnel. A.T. Crislip fait l'historique de la question en commentant les soins existant dans la famille romaine, ainsi que dans les institutions philanthropiques. Il survole la pratique dans les familles chrétiennes et juives. L'auteur examine la question du monastère remplaçant la famille et évoque les services rendus dans la famille monastique y compris ceux concernant les vêtements (Voir l'article de R.G. Coquin, «À propos des vêtements des moines égyptiens ", Bulletin de la Société d'Archéologie Copte, 31, 1992, p. 3-24; K.C. Innemée, Ecclesiastical Dress in the medieval Near East, Leyde 1992; Y.N. Youssef, "Contribution à l'étude des vêtements monastiques", Abr Nahrayn, 34, 1996-1997, p. 118-121), le logement, l'alimentation et les soins médicaux. Il est à noter que le livre de E. Wipszycka (Les ressources et les activités économiques des Églises en Égypte $d u \mathrm{IV}^{e}$ au $\mathrm{VII}^{e}$ siècle, Bruxelles, Fondation égyptologique Reine Elizabeth, 1972) qui contient plusieurs informations papyrologiques sur les activités philanthropiques de l'Église en Égypte est absent de cette recherche.

5 Le troisième chapitre est consacré à l'étude du monde social monastique pour la maladie et la santé. L'auteur souligne l'importance du malade dans le système monastique avant d'étudier les conséquences de sa présence: exemption du travail, prière, régime alimentaire (déjà évoqué en partie dans le premier chapitre) et autres charges. L'auteur parle de l'interdiction du vin dans les monastères alors que plusieurs apophtegmes mentionnent sa consommation à l'occasion des fêtes: les fouilles de Saqqarah ont mis au jour un calendrier liturgique avec les dates des fêtes et les quantités du vin nécessaire pour les célébrer ( $C f$. Quibell, Excavations in Saqqara 1910-1912).

6 L'étude se poursuit avec l'analyse des réactions négatives envers les malades. Il est à noter que deux pères de l'Église ont été ramenés à leur monastère pour y recevoir les soins nécessaires : Jean Chrysostome et Sévère d'Antioche ( $c f$. M.A. Kugener, «Vie de Sévère par Jean supérieur du Monastère de Beith Aphthonia ", Paris, Patrologia Orientalis II/3, 1907, p. 259-260).

7 Le dernier chapitre parle de la transformation du monachisme et la naissance de l'hôpital. Comme d'habitude, l'auteur survole la question avant de passer à l'essentiel à savoir le rôle de saint Basile. Il étudie les soins offerts aux pauvres, orphelins, lépreux, les étrangers et les sans-domiciles, les personnes âgées et les infirmes. L'auteur donne également les antécédents des hôpitaux de saint Basile, entre autres les temples d'Asclepius, les cliniques des docteurs, les infirmiers et les esclaves.

8 On peut regretter l'absence des martyrs Jean et Cyr, Côme et Damien et Collothus connus comme médecins "anargyroi» (= qui soignent sans frais) ( $C f$. Otto Meinardus, Coptic Saints and Pilgrimages, Cairo, American University Press in Cairo, 2002, p. 39-43). Par ailleurs, il faut rappeler que plusieurs chercheurs, dont Gribomont, doutent de l'authenticité des traités ascétiques de saint Basile mentionnés à la page 103.

9 Le livre met à la disposition du lecteur plusieurs textes inédits de saint Chénouté mais, dans les notes, il renvoie à des sigles sans donner les références. Les coptisants 
reconnaîtront facilement le système d'Orlandi-Emmel mais il aurait fallu le préciser pour le lecteur non spécialiste.

10 Le style de l'auteur est limpide et facile à lire. Les idées sont bien structurées. Le livre est extrêmement intéressant tant pour le spécialiste que pour le non spécialiste. Nous ne pouvons que féliciter l'auteur pour ce livre qui éclaire d'un jour nouveau une question peu étudiée et qui comble une lacune dans la bibliographie chrétienne en générale, copte en particulier. Les quelques remarques que nous avons émises, n'enlèvent rien à l'intérêt que nous avons pris à la lecture de cet ouvrage. 